\title{
ПРОБЛЕМЫ КОРРОЗИИ И ФИЗИКО-МЕХАНИЧЕСКИЕ МОДЕЛИ РАЗРУШЕНИЯ КОНСТРУКЦИОННЫХ МАТЕРИАЛОВ ДЛЯ ЭНЕРГОМАШИНОСТРОЕНИЯ
}

\author{
Заворин Александр Сергеевич', \\ zavorin@tpu.ru
}

Любимова Людмила Леонидовна', II@tpu.ru

Буваков Константин Владимирович', buvakov@tpu.ru

\author{
Шмитов Денис Максимович 1 \\ dms4@tpu.ru
}

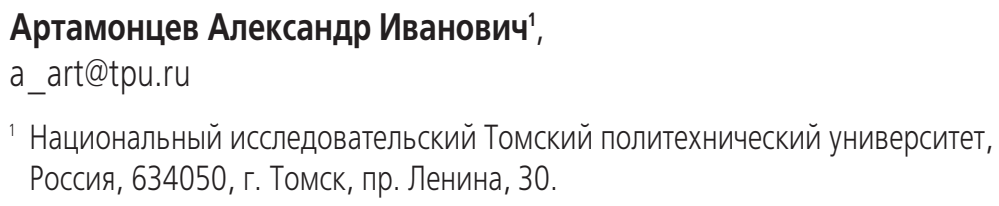

Актуальность исследования обусловлена необходимостью увеличения ресурса тепломеханического оборудования вследствие снижения потерь металла от коррозионных повреждений. Продление ресурса и диагностирование состояния конструкционных материалов энергетического оборудования обусловлено нарастанием степени его износа на действующих электростанциях. В связи с этим требуется тщательный анализ существующих механизмов образования и разрушения оксидных пленок, образования микротрещин, эволюции микротрещин с последующим развитием макротрещин и структурных факторов, влияющих на эти механизмы. Это будет способствовать подготовки к переходу на качественно более информативный масштабный уровень исследований - наноразмерный и даже атомный, без чего невозможно кардинально решать задачи сбережения материалов, используемых для изготовления элементов энергетического оборудования, эксплуатируемых в условиях высоких температур и давления среды.

Цель: анализ состояния проблемы в направлении надежного выявления признаков предкоррозионного разрушения, а также установления механизмов последующей коррозии поверхностей нагрева парогенераторов и других теплообменных установок для получения объективных сведений о коррозионной стойкости и жаропрочности сталей для изделий энергетического машиностроения, а также с целью создания информационной базы для обоснования задач и методологии исследований в этом направлении.

Результаты исследования состояния проблемы. Установлены определяющие механизмы коррозионного разрушения под действием эксплуатационных факторов. Углубление понимания закономерностей действия этих факторов требует получения результатов наблюдения не только в статичном стоянии объекта исследований, но и в динамике их изменения.

\section{Ключевые слова:}

Сталь, коррозионное растрескивание под напряжением, межкристаллитная коррозия, пассивирующие пленки, размер зерна, внутренние напряжения, микроструктура.

\section{Введение}

Коррозия - это явление деградации металлического материала в результате химического или электрохимического взаимодействия с окружающей средой. Большинство металлов (и, следовательно, сплавов) являются реактивными в своих функциональных средах. Кроме того, коррозия принимает различные формы, поскольку металлы и сплавы различных типов подвергаются воздействию самых разнообразных агрессивных сред. Несмотря на это, понимание многофункционального процесса коррозии значительно продвинуто благодаря постоянно растущему количеству исследований, проводимых для изучения явлений коррозии и их распространения, а также для тестирования и проверки различных средств для уменьшения коррозии и разработки защиты от коррозии [1-3].
Отрасль науки, изучающая этот процесс, включает: физику поверхности; электрохимию; физическую, неорганическую и аналитическую химию; физику; материаловедение; металлургию; и, наконец, собственную теорию, которая включает в себя как моделирование, так и симуляцию. Главные реакции, которые способствуют водной коррозии, являются электрохимическими по природе и по этой причине могут быть разложены на анодное растворение металла и соответствующие катодные реакции выделения водорода и восстановления кислорода. Факторы, которые могут влиять на эти реакции и таким образом на общий процесс коррозии, включают структуру и состав объемной твердой фазы, а также состав электролита и изменения, которые эти системы претерпевают в процессе коррозии [1-3]. 
В данной работе на основе обзоров публикаций научных работ представлены данные о существующих механизмах образования и разрушения оксидных пленок, образования микротрещин, эволюции микротрещин с образованием макротрещин с точки зрения изменения микроструктуры сталей и структурных факторов, влияющих на эти механизмы.

\section{Механизмы разрушения пассивности}

Пассивность является результатом наличия оксидной пленки на поверхности сталей. Оксидная пленка либо термодинамически стабильна, либо очень медленно растворяется, что в том и в другом случае защищает металл от коррозии. Большинство пассивирующих металл пленок являются кристаллическими, самовосстанавливающимися и могут реформироваться при локальном разложении или удалении в результате разрушения. Самовосстановление ухудшается в присутствии агрессивных анионов, что способствует инициированию локальной коррозии [4]. Потеря пассивности, приводящая к локальной коррозии или точечной коррозии в пассивных металлах, является результатом механизмов: проникновения, предполагающего перенос анионов через оксидную пленку на поверхность металла, и разрушения пленки, сопровождающегося разрывами, которые обеспечивают прямой доступ анионов к незащищенной металлической поверхности; механизма подавления заживления, который включает непрерывные события разрушения и восстановления пассивной пленки; механизма адсорбции агрессивных анионов на поверхности оксида, что усиливает каталитическую передачу катионов металлов из оксида в электролит. Последний эффект приводит к истончению пассивного слоя с возможным окончательным полным удалением и началом интенсивного локального растворения $[1,2,5]$.

На основе работ [4-17], выполненных методами рентгеновской дифракции, сканирующей микроскопии, рентгеновской фотоэлектронной спектроскопии, наблюдаются следующие общие признаки. Продукты коррозии в аустенитных сталях состоят из пористого внешнего и плотного внутреннего оксидного слоя. Внешний пористый оксидный слой состоит в основном из железоникелевых оксидов $\mathrm{Me}_{3} \mathrm{O}_{4}$ и образуется путем диффузии ионов железа к поверхности раздела сталь/среда, диффузия может проходить как по зернам, так и через границы зерен, однако границы зерен имеют большую диффузионную способность. Внутренний слой образуется за счет окисления ионов хрома и действует как защитный барьер против дальнейшей диффузии ионов железа наружу, а также внутренней диффузии ионов кислорода. Истощение $\mathrm{Cr}$ и $\mathrm{Fe}$, сопровождаемое обогащением $\mathrm{Ni}$, объясняется диффузионной миграцией границ зерен в результате накоплений вакансий и дислокаций [18]. Миграция границ зерен происходила, когда растворенные элементы (такие как $\mathrm{Cr}$ и $\mathrm{Fe}$ ) были избирательно окислены. В работе [19] отмечается, что ускоренное межзеренное окисление является результатом истощения $\mathrm{Cr}$ в зоне диффузионной миграции зерен. Как только трещина распространяется в зону, обедненную $\mathrm{Cr}$, трудно образовать непрерывный и компактный оксид, обогащенный $\mathrm{Cr}$, и окисление распространяется впереди кончиков трещины. В работе [20] авторы также отмечают, что пористый внешний слой растет посредством механизма растворения металла и осаждения оксидов. Одновременно $\mathrm{Fe}$ и $\mathrm{Ni}$ могут селективно растворяться на активных участках. При увеличении концентрации растворенных ионов металлов катионы металлов могут объединяться с анионами с образованием оксидов или гидроксидов и осаждаться на поверхности металла. $\mathrm{Cr}$ coxраняется и обогащается во внутреннем слое ввиду наименьшей скорости диффузии. Окисление границ зерен сопровождается снижением предела прочности и текучести, что в сочетании с приложенными растягивающими напряжениями становится причиной локального растрескивания оксидной пленки и дальнейшей межкристаллитной коррозии. В работе [19] авторы предполагают, что, поскольку оксид внешней поверхности непосредственно подвергался воздействию воды, потенциал коррозии в этой области выше, чем на границах зерен под поверхностной оксидной пленкой. Более высокий коррозионный потенциал может окислить часть металлических $\mathrm{Fe}$ и $\mathrm{Ni}$ и образовать компактную шпинель $\mathrm{Cr}-\mathrm{Fe}-\mathrm{Ni}$. В то время как более низкий коррозионный потенциал на границах зерен под поверхностной оксидной пленкой мог только селективно окислять $\mathrm{Cr}$, а металлические $\mathrm{Fe}$ и $\mathrm{Ni}$ были вытеснены в окружающие зерна, примыкающие к границам. Селективное окисление $\mathrm{Cr}$ может привести к разделению осадков оксида $\mathrm{Cr}$ и металлических $\mathrm{Fe}$ и $\mathrm{Ni}$, что приведет к появлению вакансий или пор. Следовательно, нанопоры, вызванные селективным окислением, могут объяснить, почему пористость межзеренного оксида выше, чем у оксида внешней поверхности.

В работе [21] отмечается, что на морфологию внутреннего оксидного слоя оказала большое влияние предварительная обработка поверхности. В обработанных образцах слой оксида был толстым и пористым, как и толщина ультрамелкозернистого деформационного слоя. Более быстрое окисление происходило на обработанных поверхностях и приводило к образованию высокопористого, менее защитного слоя оксида. На образцах без деформации (электрополированных) оксидный слой был более компактным, что предполагает более низкую скорость переноса массы и более низкую скорость коррозии.

В работе [22] было выполнено исследование коррозионного поведения стали $16 \mathrm{Cr}-3 \mathrm{Al}$ в воде сверхкритических параметров в течении различного времени. Полученные оксидные пленки характеризовали методами рентгеновской дифракции, рентгеновской фотоэлектронной спектроско- 
пии, сканирующей, просвечивающей электронной микроскопии. Анализ поверхностных оксидов показал, что содержание оксидов, богатых $\mathrm{Cr}$, растет с увеличением времени выдержки в воде. На поверхности образца формировался внешний слой $(\mathrm{Cr}, \mathrm{Fe})_{2} \mathrm{O}_{3}$ и внутренний слой $\mathrm{Al}_{2} \mathrm{O}_{3}$. На ранних этапах коррозии скорость образования слоя оксида алюминия была выше, что объяснялось меньшей энергией Гиббса образования. При образовании непрерывного слоя $\mathrm{Al}_{2} \mathrm{O}_{3}$ рост оксида определялся диффузией. Поскольку содержание $\mathrm{Fe}$ и $\mathrm{Cr}$ выше, внешний слой стал расти быстрее, чем внутренний. С образованием компактного слоя оксида алюминия диффузия ионов железа и хрома значительно ограничивается.

В работе [23] авторы описали механизм поверхностного окисления нержавеющей стали $316 \mathrm{~L}$ в воде при температуре $340^{\circ} \mathrm{C}$. Как только образец подвергается воздействию воды, происходит окисление вдоль каналов быстрой диффузии (возможно, дислокационных каналов), вводимых путем предшествовавшей механической обработки стали. $\mathrm{Cr}$ сначала окисляется внутренней диффузией $\mathrm{O}$, a Fe диффундирует из-за его более высокой скорости диффузии. Поскольку Ni имеет меньшую скорость диффузии, чем $\mathrm{Cr}$ и $\mathrm{Fe}$, он «вытесняется» из оксида в соседнюю матрицу (занимая вакансии, оставленные $\mathrm{Fe}$ и $\mathrm{Cr}$ ). Богатые железом частицы оксида, которые могут включать катионы из окружающей среды, начинают осаждаться на внешней поверхности. Размер частиц оксида внешней поверхности увеличивается со временем воздействия, и окисление поверхности развивается в более глубокую область, образуя сплошной внутренний оксидный слой, богатый $\mathrm{Cr}$. Внутренний оксидный слой не предотвращает полностью окисление, очевидно, из-за образования проникающего окислительного слоя перед внутренним оксидным слоем. Часть $\mathrm{Ni}$ во внутреннем оксидном слое, обогащенном $\mathrm{Cr}$, «выталкивается» в проникающий окислительный слой, что приводит к локальному обогащению. Большинство $\mathrm{Fe}$ и $\mathrm{Ni}$ во внутреннем слое, обогащенном $\mathrm{Cr}$, диффундируют в окружающую среду и затем осаждаются на поверхности, образуя частицы внешнего оксида. С увеличением толщины внутреннего оксидного слоя диффузия металлических элементов наружу замедляется. После достаточно длительного воздействия растворение $\mathrm{Cr}$ из внутреннего оксидного слоя в окружающую среду приводит к истощению $\mathrm{Cr}$ верхней части, которая в конечном итоге становится аморфной. Этот новый слой нестабилен и начинает растворяться в воде с высокой температурой. В какой-то момент он теряет свою защитную природу, и окисление начинает распространяться глубже в матрицу.

Анодное растворение материалов играет центральную роль в процессе коррозии, так как является прямой причиной разрушения материала $[2,3]$. Механизм растворения включает поверхностную адсорбцию воды и последующую диссоциацию, и реакцию с поверхностью железа. Анодное растворение предполагает наличие промежуточных поверхностных связей между металлическим состоянием и частицами раствора. В работе [1] на основе исследований на чистых металлах с использованием методов, применяемых для моделирования поверхностей раздела «твердое тело-жидкость» и в сочетании с теоретическими подходами, основанными на атомистическом моделировании, отмечается, что главную роль на поверхности играют недостаточно скоординированные атомные сайты, в результате чего активное растворение протекает в виде последовательного потока с поверхностной атомной структурой. Слои сильно адсорбированных анионов не изменяют этот механизм. В присутствии пассивирующих оксидов механизм растворения становится предпочтительным в неупорядоченных местах защитного слоя, в результате происходит нанопитирование. Основным защитным эффектом поверхностных слоев является подавление поверхностной диффузии.

Пассивные пленки на нержавеющих сталях, в большинстве случаев поликристаллические и текстурированные с наноразмерными зернами. Зерна обнажают ограненную поверхность, потому что оксидная решетка растет в наклоненной эпитаксии на металлической решетке [1]. На нержавеющей стали обогащение $\mathrm{Cr}$ пассивных пленок может быть неоднородным, влияя на локальное сопротивление локальному инициированию коррозии. Границы зерен в пассивных пленках оксида на металлах являются дефектными участками, где пассивные пленки разрушаются и начинается локальная коррозия. Поверхность оксидов разрушается по механизму растворения-осаждения для внешних железоникелевых слоев $\mathrm{Me}_{3} \mathrm{O}_{4}$ (Ме обозначает железо или никель) и механизму диффузии-окисления для внутреннего $\mathrm{Cr}_{2} \mathrm{O}_{3}$ или $\mathrm{CrO}$ или $\mathrm{NiO}$. Механизм растворения включает электрохимическое селективное растворение атомов металла с образованием ионов железа и никеля [24], что соответствует электрохимической природе коррозии. Селективное растворение может быть связано с появлением пористых участков на внешнем оксидном слое, что снижает коррозионную стойкость. Механизм диффузии-окисления сопровождается образованием оксида $\mathrm{Cr}$ и $\mathrm{Ni}$ в результате диффузии окислителя через пассивную пленку и окислением на поверхности металла в области границ зерен. Растрескивание хрупких оксидов происходит под воздействием растягивающих деформаций в результате образования дислокаций вокруг оксидов [25-28], таким образом происходит диффузионная миграция границ зерен. Обогащение $\mathrm{Cr}$ пассивной пленки может быть неоднородным на наноразмерном уровне и варьироваться в зависимости от оксидных нанозерен, составляющих барьерный слой пассивной пленки [4]. Следовательно, механизмы, с помощью которых $\mathrm{Cr}$ расходуется в самых верхних слоях сплава при начальном окислении и впоследствии при электрохимической пассивации, являются ключевыми факто- 
рами для разрушения пассивности и самовосстановления, а также для инициирования локальной коррозии и требуют дальнейшего изучения с помощью спектроскопических, микроскопических и рентгеновских методов.

\section{Механизмы и структурные аспекты коррозии}

Существует много механизмов коррозии, разделение начинается с общей и локальной коррозии. Наиболее опасной является локальная коррозия, которая происходит в форме растрескивания под напряжением (КРН), точечной коррозии, гальванической коррозии, щелевой коррозии, а также межкристаллитной и расслоенной коррозии [29]. Локальная коррозия происходит в результате нарушения пассивности агрессивными веществами (например, ионами хлора). В настоящее время требуется многомасштабное (от микрометра до нанометра) понимание механизмов коррозионного растрескивания под напряжением, таких как модель разрушения оксидной пленки, водородных механизмов, механизмов внутреннего окисления, межзеренной коррозии, миграции границ зерен [13].

\section{Коррозионное растрескивание под напряжением}

Коррозионное растрескивание под напряжением понимается как разрушение металла при воздействии растягивающих напряжений и агрессивной среды. На сегодняшний день был предложен ряд механизмов для объяснения поведения КРН, включая механизм разрыва пленки, механизм водородного охрупчивания, механизм формирования полости и механизм межзеренного селективного окисления [19].

Согласно механизму межзеренного селективного окисления, основное предположение состоит в том, что границы зерен предпочтительно окисляются после воздействия воды, становясь хрупкими и, следовательно, подверженными растрескиванию. Хрупкие механические свойства границ окисленных зерен при внешней нагрузке были экспериментально обнаружены многими исследователями [26, 30, 31] с помощью микромеханических испытаний.

Эволюция границы зерен, часто в условиях напряжений и диффузии, усиленной коррозией, путем перемещения на короткие расстояния через кристалл и одновременного роста одного зерна за счет другого, называется миграцией границ зерен. Это явление, возможно, усиливается вблизи дислокаций или деформаций решетки [13].

Остаточные напряжения являются одним из наиболее важных факторов, способствующих КРН. В работе [32] сообщили, что совместное влияние тяжелой пластической деформации и остаточных напряжений, возникших вследствие механической обработки, снижало сопротивление хлористому КРН в аустенитной нержавеющей стали, даже в отсутствие каких-либо внешних воздействующих нагрузок. Данное исследование также показало, что микротрещины инициировались в зоне растягивающего напряжения и были остановлены в зоне сжимающего напряжения.

В работах [19, 29, 33, 34] было изучено влияние механической обработки нержавеющей стали на инициирование КРН при различных уровнях остаточных напряжений. Общей особенностью микротрещин является то, что направление растрескивания перпендикулярно направлению обработки (на вертикальном фрезерном станке). Объясняется это возникшим в результате высоким уровнем растягивающих напряжений. Рост уровня напряжения приводил к повышению плотности и скорости инициирования микротрещин. Образование микротрещин становилось значительным при достижении критического значения напряжений, для нержавеющей аустенитной стали 316 оно составило $190 \mathrm{MПа} \mathrm{[33].} \mathrm{В} \mathrm{работах} \mathrm{[29,} \mathrm{34]} \mathrm{отмечается,} \mathrm{что}$ операция полировки улучшила сопротивление КРН, благодаря синергии трех факторов: сжимающих напряжений, минимальной пластической деформации и улучшенной шероховатости поверхности. В работе [19] методом сканирующей электронной микроскопии высокого разрешения в результате полировки в сплаве 600 был обнаружен тонкий слой зоны деформации (200-700 нм), состоящий из наноразмерных рекристаллизованных зерен. Границы зерен преимущественно состояли из пористых карбидов. Межзеренное окисление протекало по вновь образованным границам и прекращалось на границе раздела «деформационный слой-металл». Как только микротрещины в деформационном слое пересекали границы зерен окисленной матрицы, они распространялись вдоль этих границ зерен и образовывали новые макротрещины. Распространение трещины вдоль границ зерен матрицы можно объяснить механизмом межзеренного селективного окисления. В работе [35] отмечается, что механическая обработка, как и шлифование, увеличивали стойкость к инициации КРН, частичное удаление выступов меток обработки снижает остаточное напряжение, вызванное обработкой. Однако это уменьшило сопротивление инициированию КРН, следовательно, роль микроструктуры является определяющей на ранних стадиях зарождения трещины [21]. В работе [36] авторы утверждают, что коррозия может быть механизмом, управляемым напряжением, то есть локальная точечная коррозия ускоряется гетерогенными напряжениями, формирующимися относительно микроструктурных особенностей.

В работе [37] сообщается, что трещины имеют тенденцию образовываться из предшествующей коррозионной ямы, трещины развиваются преимущественно в плечевой части ямы для образцов, напряженных до 50-90 \% $\sigma_{0,2}$, вблизи границы раздела «яма-поверхность». Трехмерные топографические изображения, характеризующие ранние стадии развития трещин, позволяют предположить, что трещины, образовавшиеся на стенках ямы, могут расти вокруг ямы и образовывать целую сквозную трещину. Слияние трещин из одной 
и той же ямы, вероятно, будет ключевым фактором в развитии трещин в процессе эксплуатации.

Тем не менее, большинство из этих исследований были сосредоточены на стадии распространения трещины, а не на инициации, из-за сложности доступа к микротрещинам на ранней стадии инициации и, следовательно, связь между механистическим пониманием и предсказанием КРН все еще отсутствует.

\section{Межкристаллитная и точечная коррозия}

Межкристаллитная коррозия (МКК) является формой локальной коррозии для металлов и сплавов в активном состоянии, то есть когда не образуются пассивирующие пленки или образуются пленки с малозащитным действием в зависимости от условий окружающей среды. Межкристаллитная коррозия также происходит в присутствии хорошо пассивирующей оксидной пленки, например, при коррозионном растрескивании под межзеренным напряжением [4].

Точечная коррозия является предшественником коррозионного растрескивания под напряжением, поскольку она обеспечивает требуемую комбинацию агрессивного локального химического состава раствора и функции концентрации напряжений. Микроструктура, как и форма развивающейся ямы, будут непосредственно влиять на локальные значения концентрации напряжений, что приведет к возникновению трещин. Большинство исследований точечной коррозии рассматривали это явление с электрохимической и композиционной точек зрения в макромасштабе и не учитывали микроструктуру и изменения формы развивающейся ямы с течением времени. Исследования методами сканирующей электронной микроскопии, сканирующего вибрирующего электрода, зондовой микроскопии Кельвина и рентгеновской компьютерной микроскопии показали, что возникновение точечной коррозии сильно зависит от микроструктурных особенностей на корродирующей поверхности. Ими могут быть, например, включения, частицы второй фазы, агрегированные в растворе границы зерен, формы зерен, кристаллографические ориентации, дефекты, механические повреждения и плотность дислокаций [38].

Морфология и распределение карбидов в границах зерен считаются важными факторами, влияющими на область обеднения хрома и, следовательно, стойкость к МКК. Показано, что межзеренная коррозия, наблюдаемая в результате проникновения под поверхность зернограничной микроструктуры, тесно связана с кристаллографическим характером и энергией границ зерен [39-46].

Структура границ зерен может быть частично описана моделью решетки совпадающих узлов $\left(\sum n\right.$, где $n-$ число атомов в одной ячейке). Исследования углов разориентировки в сталях показывают, что восприимчивость к коррозии может зависеть от распределения ориентации зерен на межзеренных границах, поскольку энергия границ зерен определяется структурой границ. Низкоугловые границы зерен, имеющие угол разориентации $\left(<15^{\circ}\right)$, считаются устойчивыми к межкристаллитной коррозии из-за их меньшей энергии по сравнению с высокоугловыми границами зерен [4, 47]. В работе [48] авторы характеризуют низкоугловые границы как массивы краевых дислокаций, а высокоугловые - как имеющие одну или несколько повторяющихся многогранных структурных единиц. В работе [13] отмечается, что увеличение наклона границы зерна приводит к наибольшему нормальному напряжению на границе зерна, что делает его более подверженным растрескиванию.

Многие исследователи показали, что определенные кристаллографические ориентации, такие как $\Sigma 3, \Sigma 3 n$, способствовали повышению устойчивости к МКК $[4,39,46,49]$. Такие границы называют специальными. В работе [50] исследование микроструктуры стали после старения показало осаждение карбидов вдоль границ зерен. Карбиды снизили микротвердость, пластичность и предел текучести и как следствие повышение потери массы от коррозии. В работе [51] была исследована микроструктура отожжённого в вакууме никелевого нанокристаллического покрытия. В металлах и сплавах на основе железа с гранецентрированной кубической решеткой в процессе отжига образуются двойники отжига. Двойники имеют когерентные двойниковые границы, которые представляют собой высокоугловые специальные границы. Результаты исследования показали, что плотность двойников и размер зерна важны для коррозионной стойкости материалов, но влияние плотности двойников превосходит влияние размера зерен.

Сведения о влиянии размеров зерна на коррозионное поведение противоречивы. В работе [52] исследовано коррозионное поведение магниевых сплавов с крупно- и мелкозернистой структурой. Мелкозернистая показала высшую микротвердость и коррозионную стойкость. С увеличением площади границ зерен посредством измельчения зерен несоответствие между пассивирующей пленкой и металлической матрицей (несоответствие параметров решеток пленки и подложки) было уменьшено, и, таким образом, усилие межфазного сцепления было увеличено. В работе [6] было обнаружено, что ниже критического среднего размера зерна более высокая доля границ зерен вызывает образование защитного слоя оксида хрома. Оксидный слой был достаточно толстым и непрерывным, чтобы уменьшить скорость диффузии ионов железа и ионов кислорода, и в результате скорость окисления резко снизилась. Однако в работе [53] отмечается более низкая коррозионная стойкость мелкозернистой структуры. Это может быть связано с тем, что мелкозернистая микроструктура имеет более высокую химическую активность и более отрицательные потенциалы разряда, чем крупнозернистая. Плотность границ зерен увеличивается с измельчением зерна, что приводит к более высоким скоростям растворения и диффузии для атомов. 
В работе [54] исследовано коррозионное поведение аморфных покрытий на основе железа с различной геометрией, которые давали различный уровень остаточных напряжений. Покрытия, которые имели высокое остаточное напряжение при растяжении, демонстрировали более высокую плотность пассивного тока (определяется ионной проводимостью), чем те, которые имели низкое остаточное напряжение при растяжении. Вредный эффект остаточного напряжения усиливался при более высоких температурах и кислотности среды. Предполагается, что растягивающие остаточные напряжения ускоряют локализованную коррозионную восприимчивость покрытий вблизи пор, образуя микротрещины и способствуя быстрой диффузии для ионов. Пассивирующая пленка покрытия с наибольшим остаточным напряжением сформировалась с высокой плотностью доноров, что также может быть причиной более низкой локальной коррозионной стойкости.

Ориентация зерна может оказывать значительное влияние на поведение сегрегаций легирующих элементов и как следствие на коррозионную стойкость сталей [38]. В работах [38, 55] показано, что наиболее чувствительной поверхностью к точечной коррозии являются плоскости, ориентированные вблизи (001), тогда как плоскости (111) и (110) с более высокой атомной плотностью имеют более высокую стойкость к точечной коррозии. В работе [56], посвященной исследованию эффекта кристаллографической ориентации для листов ферритной стали, отмечается, что наиболее сильная коррозия происходит на поверхности листа, где кристаллические плоскости (111) большинства зерен феррита параллельны поверхности листа. Кристаллографическая ориентация влияет на скорость появления и распространения ям коррозии. Характеристики плотной упаковки кристаллических плоскостей, плотности дефектов в микромасштабах и изменения скорости реакции были описаны как возможные причины такого поведения; однако точные корреляции остаются неоднозначными. Эта неоднозначность может быть в первую очередь связана с трудностями, связанными с регистрацией сложных экспериментальных наблюдений.

Межкристаллитное растрескивание может быть результатом снижения предела текучести областей границ зерен, которые были окислены или корродированы, или снижения предела прочности на разрыв или сдвига и когезионной энергии областей границ зерен [49]. Более низкое сопротивление точечной коррозии будет иметь место для кристаллографических плоскостей с меньшей плотностью упаковки атомов. Низкоугловые границы, а также «специальные» высокоугловые границы способствуют повышению сопротивления коррозии.

\section{Заключение}

На основе обзора публикаций научных работ были систематизированы данные о физико-меха- нических основах образования и разрушения оксидных пленок, образования микротрещин, эволюции микротрещин с образованием макротрещин с точки зрения изменения микроструктуры сталей и структурных факторов, влияющих на эти механизмы.

Пассивные пленки на нержавеющих сталях в большинстве случаев поликристаллические и текстурированные наноразмерными зернами. Продукты коррозии состоят из пористого внешнего и плотного внутреннего оксидного слоя. Внешний пористый оксидный слой нержавеющих сталей состоит в основном из железоникелевых оксидов, внутренний слой образуется за счет окисления ионов хрома и действует как защитный барьер против дальнейшей диффузии ионов железа наружу, а также внутренней диффузии ионов кислорода. Пористый внешний слой растет посредством механизма селективного растворения металла и осаждения оксидов. $\mathrm{Cr}$ сохраняется и обогащается во внутреннем слое ввиду наименьшей скорости диффузии. Межзеренные границы являются предпочтительными местами для протекания коррозии. Окисление границ зерен сопровождается снижением предела прочности и текучести, что в сочетании с приложенными растягивающими напряжениями становится причиной локального растрескивания оксидной пленки и дальнейшей межкристаллитной коррозии. Протекание межкристаллитной коррозии зависит от морфологии и распределения карбидов в границах зерен и тесно связано с кристаллографическим характером и энергией границ зерен. Отмечается, что низкоугловые границы, а также «специальные» высокоугловые границы способствуют сопротивлению коррозии. Влияние размеров зерна на коррозию неоднозначно: с одной стороны, отмечается, что мелкозернистая структура способствует образованию более плотного защитного слоя хрома, в то же время увеличение плотности границ зерен приводит к более высоким скоростям диффузии. Ориентация зерна может оказывать значительное влияние на коррозионную стойкость стали. Отмечается, что плоскости, ориентированные вблизи (111) и (110) с более высокой атомной плотностью, имеют более высокую стойкость к точечной коррозии, однако корреляции остаются неоднозначными в связи с трудностями, связанными с регистрацией сложных экспериментальных наблюдений. Микроструктура, как и форма развивающейся ямы, будет непосредственно влиять на локальные значения концентрации напряжений, что приведет к возникновению трещин. Напряжение не может использоваться в качестве критерия подверженности коррозии, однако коррозия может быть механизмом, управляемым напряжением, формирующимся относительно микроструктурных особенностей. Микротрещины инициируются в зоне растягивающего напряжения и останавливаются в зоне сжимающего напряжения. Перераспределе- 
ние напряжения может быть связано с локальной релаксацией (образованием микротрещин), а также с миграцией границ зерен в результате селективного окисления. Таким образом, понимание процессов, происходящих на границах зерен, является важным фактором в повышении коррозионной стойкости материалов.

\section{СПИСОК ЛИТЕРАТУРЫ REFERENCES}

1. Maurice V., Marcus P. Progress in corrosion science at atomic and nanometric scales. Progress in Materials Science, 2018, vol. 95, pp. 132-171.

2. Marcus P. Corrosion mechanisms in theory and practice. Boca Raton, CRC Press Publ., 2012. 905 p.

3. Taylor C.D., Marcus P. Molecular modeling of corrosion processes: Scientific development and engineering applications. Hoboken, John Wiley \& Sons, Inc., 2015. 256 p.

4. Maurice V., Marcus P. Current developments of nanoscale insight into corrosion protection by passive oxide films. Current opinion in solid state and materials science, 2018, vol. 22, no. 4 pp. $156-167$.

5. Soltis J. Passivity breakdown, pit initiation and propagation of pits in metallic materials - review. Corrosion Science, 2015, vol. 90 , pp. 5-22.

6. Nezakat M., Akhiani H., Penttil? S., Sabet S.M., Szpunar J. Effect of thermo-mechanical processing on oxidation of austenitic stainless steel 316L in supercritical water. Corrosion Science, 2015, vol. 94, pp. 197-206.

7. Han Y., Mei J., Peng Q., Han E.-H., Ke W. Effect of electropolishing on corrosion of Alloy 600 in high temperature water. Cor rosion Science, 2015, vol. 98, pp. 72-80.

8. Lim Y.S., Kim H.P., Hwang S.S. Microstructural characterization on intergranular stress corrosion cracking of Alloy 600 in PWR primary water environment. Journal of Nuclear Materials, 2013, vol. 440, no. 1-3, pp. 46-54.

9. Huang F., Wang J., Han E.-H., Ke W. Microstructural characteristics of the oxide films formed on Alloy 690 TT in pure and primary water at $325^{\circ} \mathrm{C}$. Corrosion Science, 2013, vol. 76, pp. 52-59.

10. Wang W., Zhang Z., Ren X., Guan Y., Su Y. Corrosion product film-induced stress facilitates stress corrosion cracking. Scienti fic Reports, 2015, vol. 5, no. 1, pp. 10579.

11. Kruska K., Lozano-Perez S., Saxey D.W., Terachi T., Yamada T., Smith G.D.W. Nanoscale characterisation of grain boundary oxidation in cold-worked stainless steels. Corrosion Science, 2012, vol. 63 , pp. 225-233.

12. Meisnar M., Moody M., Lozano-Perez S. Atom probe tomography of stress corrosion crack tips in SUS316 stainless steels. Corrosion Science, 2015, vol. 98, pp. 661-671.

13. Meisnar M., Vilalta-Clemente A., Gholinia A., Moody M., Wilkinson A.J., Huin N., Lozano-Perez S. Using transmission Kikuchi diffraction to study intergranular stress corrosion cracking in type 316 stainless steels. Micron, 2015, vol. 75, pp. 1-10.

14. Lim Y.S., Kim S.W., Hwang S.S., Kim H.P., Jang C. Intergranular oxidation of Ni-based Alloy 600 in a simulated PWR primary water environment. Corrosion Science, 2016, vol. 108, pp. 125-133.

15. Persaud S.Y., Korinek A., Huang J., Botton G.A., Newman R.C. Internal oxidation of Alloy 600 exposed to hydrogenated steam and the beneficial effects of thermal treatment. Corrosion Science, 2014, vol. 86, pp. 108-122.

16. Bertail G., Scenini F., Burke M.G. The intergranular oxidation susceptibility of thermally-treated Alloy 600. Corrosion Science, 2017, vol. 114, pp. 112-122.
Дальнейшее понимание процессов коррозии требует не только статичных данных наблюдения, но и данных об изменении системы в режиме реального времени. При этом исследования коррозии должны проводиться в масштабах длины не только миллиметра и микрометра, но также на нано- и даже атомном уровне.

17. Arioka K., Staehle R.W., Yamada T., Miyamoyo T., Terachi T. Degradation of Alloy 690 after relatively short times. Corrosion, 2016, vol. 72, no. 10, pp. 1252-1268.

18. Azizi A., Zou X., Ercius P., Zhang Z., Elias A.L., Perea-Lopez N., Stone G., Terrones M., Yakobson B.I., Alem N. Dislocation motion and grain boundary migration in two-dimensional tungsten disulphide. Nature Communications, 2014, vol. 5, no. 1, pp. 4867.

19. Shen Z., Chen K., Tweddle D., He G., Arioka K., Lozano-Perez S. Characterization of the crack initiation and propagation in Alloy 600 with a cold-worked surface. Corrosion Science, 2019, vol. 152, pp. 82-92.

20. Zhong X., Han E.-H., Wu X. Corrosion behavior of Alloy 690 in aerated supercritical water. Corrosion Science, 2013, vol. 66, pp. 369-379.

21. Chang L., Burke M.G., Scenini F. Stress corrosion crack initiation in machined type 316L austenitic stainless steel in simulated pressurized water reactor primary water. Corrosion Science, 2018, vol. 138, pp. 54-65.

22. Ren J., Yu L., Liu Y., Ma Z., Liu C., Li H., Wu J. Corrosion behavior of an $\mathrm{Al}$ added high-Cr ODS steel in supercritical water at $600{ }^{\circ} \mathrm{C}$. Applied Surface Science, 2019, vol. 480, pp. 969-978.

23. Shen Z., Du D., Zhang L., Lozano-Perez S. An insight into PWR primary water SCC mechanisms by comparing surface and crack oxidation. Corrosion Science, 2019, vol. 148, pp. 213-227.

24. Liu X., Hwang W., Park J., Van D., Chang Y., Lee S.H., Kim S.-Y., Han S., Lee B. Toward the multiscale nature of stress corrosion cracking. Nuclear Engineering and Technology, 2018, vol. 50, no. 1, pp. 1-17.

25. Moss T., Was G.S. Accelerated stress corrosion crack initiation of alloys 600 and 690 in hydrogenated supercritical water. Metallurgical and Materials Transactions A, 2017, vol. 48, no. 4, pp. 1613-1628.

26. Dugdale H., Armstrong D.E.J., Tarleton E., Roberts S.G., Lozano-Perez S. How oxidized grain boundaries fail. Acta Materialia, 2013, vol. 61, no. 13, pp. 4707-4713.

27. Kruska K. Understanding the Mechanism of Stress Corrosion Cracking. Ph.D. thesis. Oxford, 2012. Available at: https://ora. ox.ac.uk/objects/uuid:94574eaf-4ae0-4093-bf20-3f4f4c559e7c (accessed 1 September 2019).

28. Stratulat A., Armstrong D.E.J., Roberts S.G. Micro-mechanical measurement of fracture behaviour of individual grain boundaries in Ni alloy 600 exposed to a pressurized water reactor environment. Corrosion Science, 2016, vol. 104, pp. 9-16.

29. Song Z., Xie Z.-H. A literature review of in situ transmission electron microscopy technique in corrosion studies. Micron, 2018, vol. 112, pp. 69-83.

30. Dohr J., Armstrong D.E.J, Tarleton E., Couvant T., Lozano-Perez S. The influence of surface oxides on the mechanical response of oxidized grain boundaries. Thin Solid Films, 2017, vol. 632, pp. 17-22.

31. Fujii K., Miura T., Nishioka H., Fukuya K. Degradation of grain boundary strength by oxidation in alloy $600.15^{\text {th }}$ International Conference on Environmental Degradation of Materials in Nuclear Power Systems-Water Reactors. Hoboken, John Wiley \& Sons, Inc., 2012. pp. 1447-1458.

32. Ghosh S., Rana V.P.S., Kain V., Mittal V., Baveja S.K. Role of residual stresses induced by industrial fabrication on stress cor- 
rosion cracking susceptibility of austenitic stainless steel. Materials \& Design, 2011, vol. 32, no. 7, pp. 3823-3831.

33. Zhang W., Fang K., Hu Y., Wang S., Wang X. Effect of machining-induced surface residual stress on initiation of stress corrosion cracking in 316 austenitic stainless steel. Corrosion Science, 2016, vol. 108, pp. 173-184

34. Kumar P.S., Acharyya S.G., Rao S.V.R., Kapoor K. Distinguishing effect of buffing vs. grinding, milling and turning operations on the chloride induced SCC susceptibility of 304L austenitic stainless steel. Materials Science and Engineering: A, 2017, vol. 687, pp. 193-199.

35. Chang L., Burke M.G., Scenini F. Understanding the effect of surface finish on stress corrosion crack initiation in warm-forged stainless steel 304L in high-temperature water. Scripta Materialia, 2019, vol. 164, pp. 1-5.

36. Nicolas A., Mello A.W., Sangid M.D. Relationships between microstructure and micromechanical stresses on local pitting during galvanic corrosion in AA7050. Corrosion Science, 2019, vol. 154, pp. 208-225.

37. Horner D.A., Connolly B.J., Zhou S., Crocker L., Turnbull A. Novel images of the evolution of stress corrosion cracks from corrosion pits. Corrosion Science, 2011, vol. 53, no. 11, pp. 3466-3485.

38. Brewick P.T., Kota N., Lewis A.C., De Giorgi V.G., Geltmacher A.B., Qidwai S.M. Microstructure-sensitive modeling of pitting corrosion: effect of the crystallographic orientation. Cor rosion Science, 2017, vol. 129, pp. 54-69.

39. Hu C., Xia S., Li H., Liu T., Zhou B., Chen W., Wang N. Improving the intergranular corrosion resistance of 304 stainless steel by grain boundary network control. Corrosion Science, 2011, vol. 53 , no. 5, pp. 1880-1886.

40. Luo C., Zhou X., Thompson G.E., Hughes A.E. Observations of intergranular corrosion in AA2024-T351: The influence of grain stored energy. Corrosion Science, 2012, vol. 61, pp. 35-44.

41. Kumar B.S., Prasad B.S., Kain V., Reddy J. Methods for making alloy 600 resistant to sensitization and intergranular corrosion. Corrosion Science, 2013, vol. 70, pp. 55-61.

42. Takehara Y., Fujiwara H., Miyamoto H. «Special» to «general» transition of intergranular corrosion in Sigma $3\{111\}$ grain boundary with gradually changed misorientation. Corrosion Science, 2013, vol. 77, pp. 171-175.

43. Stratulat A., Duff J.A., Marrow T.J. Grain boundary structure and intergranular stress corrosion crack initiation in high temperature water of a thermally sensitised austenitic stainless steel, observed in situ. Corrosion Science, 2014, vol. 85, pp. 428-435.

44. Martinez-Lombardia E., Gonzalez-Garcia Y., Lapeire L., De Graeve I., Verbeken K., Kestens L., Mol J.M.C., Terryn H. Scanning electrochemical microscopy to study the effect of crystallographic orientation on the electrochemical activity of pure copper. Electrochimica Acta, 2014, vol. 116, pp. 89-96.

45. Srinivasan N., Kain V., Birbilis N., Mani Krishna K.V., Shekhawat S., Samajdar I. Near boundary gradient zone and sen- sitization control in austenitic stainless steel. Corrosion Science, 2015, vol. 100 , pp. 544-555.

46. Ding Q., Zhang D., Zuo J., Hou S., Zhuang L., Zhang J. The effect of grain boundary character evolution on the intergranular corrosion behavior of advanced $\mathrm{Al}-\mathrm{Mg}-3$ wt. \% $\mathrm{Zn}$ alloy with $\mathrm{Mg}$ variation. Materials Characterization, 2018, vol. 146, pp. 47-54.

47. Yuan Y., Jiang Y, Zhou J., Liu G., Ren X. Influence of grain boundary character distribution and random high angle grain boundaries networks on intergranular corrosion in high purity copper. Materials Letters, 2019, vol. 253, pp. 424-426.

48. Choi K.J., Yoo S.C., Kim S., Kim T., Ham J., Lee J., Kim J.H. Microstructural evolution and corrosion behaviour of thermally aged dissimilar metal welds of low-alloy steel and nickel-based alloy. Corrosion Science, 2019, vol. 153, pp. 138-149.

49. Commisso M.S., Le Bourlot C., Bonnet F., Zanelatto 0., Maire E. Thermo-mechanical characterization of steel-based metal matrix composite reinforced with TiB2 particles using synchrotron X-ray diffraction. Materialia, 2019, vol. 6, pp. 100311.

50. Joseph M.J., Jabbar M.A. Effect of aging process on the microstructure, corrosion resistance and mechanical properties of stainless steel AISI 204. Case Studies in Construction Materials, 2019, vol. 11, pp. e00253.

51. Meng G., Li Y., Shao Y., Zhang T., Wang Y., Wang F., Cheng X., Dong C., Li X. Effect of microstructures on corrosion behavior of nickel coatings: (II) competitive effect of grain size and twins density on corrosion behavior. Journal of Materials Science \& Technology, 2016, vol. 32, no. 5, pp. 465-469.

52. Huang L., Wang K., Wang W., Yuan J., Qiao K., Yang T., Peng P., Li T. Effects of grain size and texture on stress corrosion cracking of friction stir processed AZ80 magnesium alloy. Engineering Failure Analysis, 2018, vol. 92, pp. 392-404.

53. Song D., Ma A.B., Jiang J.H., Lin P.H., Yang D.H., Fan J.F. Corrosion behaviour of bulk ultra-fine grained AZ91D magnesium alloy fabricated by equal-channel angular pressing. Corrosion Science, 2011, vol. 53, no. 1, pp. 362-373.

54. Wang Y., Li K.Y., Scenini F., Jiao J., Qu S.J., Luo Q., Shen J. The effect of residual stress on the electrochemical corrosion behavior of Fe-based amorphous coatings in chloride-containing solutions. Surface and Coatings Technology, 2016, vol. 302, pp. 27-38.

55. Zhang L., Szpunar J.A., Dong J., Ojo 0.A., Wang X. Dependence of crystallographic orientation on corrosion behavior of $\mathrm{Ni}-\mathrm{Fe}-\mathrm{Cr}$ alloy 028. Metallurgical and Materials Transactions B, 2018, vol. 49, no. 3, pp. 919-925.

56. Fu J., Li F., Sun J., Cui K., Du X., Wu Y. Effect of crystallographic orientations on the corrosion resistance of Fe-17Cr ferritic stainless steel. Journal of Electroanalytical Chemistry, 2019, vol. 841 , pp. 56-62.

Поступила 7.10.2019 2.

\section{Информация об авторах}

Заворин A.C., доктор технических наук, профессор научно-образовательного центра И.Н. Бутакова Национального исследовательского Томского политехнического университета.

Любимова Л.Л., кандидат технических наук, доцент научно-образовательного центра И.Н. Бутакова Национального исследовательского Томского политехнического университета.

Буваков K.B., кандидат технических наук, доцент научно-образовательного центра И.Н. Бутакова Национального исследовательского Томского политехнического университета.

Шмитов Д.М., магистрант научно-образовательного центра И.Н. Бутакова Национального исследовательского Томского политехнического университета.

Артамониев А.И., кандидат технических наук, доцент научно-образовательного центра И.Н. Бутакова Национального исследовательского Томского политехнического университета. 


\title{
CORROSION PROBLEMS AND PHYSICAL-MECHANICAL MODELS OF STRUCTURAL MATERIALS FAI- LURE FOR POWER PLANT ENGINEERING
}

\author{
Alexander S. Zavorin', \\ zavorin@tpu.ru \\ Lyudmila L. Lyubimova', \\ II@tpu.ru \\ Konstantin V. Buvakov', \\ buvakov@tpu.ru \\ Denis M. Shmitov', \\ dms4@tpu.ru

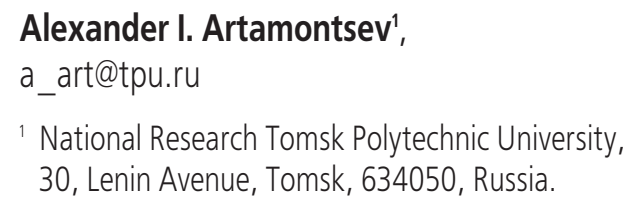

Relevance of the research is caused by the need for increase of thermal and mechanical equipment life by reducing the metal losses caused by corrosion damage. Life extension and diagnostics of the structural materials state in power equipment are induced by the growing wear rate at operating electric power plants. In this relation, a thorough analysis of current mechanisms of oxide film formation and destruction, microcracking, evolution of microcracks with their further development and structural factors, affecting these mechanisms, is required. It will promote the preparation for a transition to a qualitatively more informative and extensive level of research - nanoscale and even atomic, without which it is impossible to find dramatic solutions to the efficiency problems for materials used in manufacture of power equipment components and operated under high temperatures and pressure.

The aim of the research is to analyze the problem to find reliable indicators of pre-corrosion failure, as well as to investigate the mechanisms of further corrosion of heating surfaces in steam generators and other heat exchange systems and obtain objective data about corrosion and heat resistance of steels for power plant engineering products, and also to develop the information basis for justification of objectives and methodology of studies in this area.

Results of researching the problem. The authors have defined the mechanisms of corrosion failure affected by operational factors. Deeper insight of these factors pattern requires obtaining of observation results not only in the static state of the object, but the dynamic history as well.

Key words:

Steel, stress corrosion cracking, intergranular corrosion, passive films, grain size, internal stress, microstructure.

Received: 7 October 2019.

Information about the authors

Alexander S.Zavorin, Dr. Sc., professor, National Research Tomsk Polytechnic University.

Lyudmila L. Lyubimova, Cand. Sc., associate professor, National Research Tomsk Polytechnic University.

Konstantin V. Buvakov, Cand. Sc., associate professor, National Research Tomsk Polytechnic University.

Denis M. Shmitov, undergraduate, National Research Tomsk Polytechnic University.

Alexander I. Artamontsev, Cand. Sc., associate professor, National Research Tomsk Polytechnic University. 